\title{
Surgical treatment of hepatic hydatic disease during pregnancy: report of two cases
}

\author{
Haluk Ünalp • Çetin Aydin • Ali Yavuzcan • \\ Erdinc Kamer • Ali Baloglu
}

Received: 15 August 2007 / Accepted: 30 November 2007 / Published online: 10 January 2008

(C) Springer-Verlag 2007

\begin{abstract}
Current treatment options for hepatic hydatid disease include surgery, medical treatment, and percutaneous drainage. However, the choice between these treatment modalities for pregnant women is still controversial. We reported in this article two pregnant patients with hepatic hydatid cysts who underwent surgical treatment.
\end{abstract}

Keywords Hepatic $\cdot$ Hydatid cyst $\cdot$ Pregnancy $\cdot$ Surgery

\section{Introduction}

Hydatid disease is a parasitic disease caused by the larval stage of Echinococcous granulosus or Echinococcous multicularis, which are microscopic tapeworm. Hepatic hydatid disease is most often caused by Echinococcus granulosus. Echinococcus multicularis usually causes alveolar echinococcosis and rarely hepatic echinococcosis. Humans, contracting from infected sheep and cattle, are accidental intermediate hosts. Hydatid disease is a public health problem that is commonly seen in the Middle East, South America, some Mediterranean countries, and Australia [1]. The livers, lungs, and the bones are the organs that are most commonly involved; however, the cyst may be localized to any part of the body [2]. The incidence rate of hydatid disease during pregnancy hovers approximately $1: 20,000-30,000$ [2-4]. Experience in the management of the disease through surgery, medical treatment, and percutaneous drainage during pregnancy is limited.

\footnotetext{
H. Ünalp · Ç. Aydin · A. Yavuzcan $(\bowtie) \cdot$ E. Kamer • A. Baloglu

Ataturk Training and Research Hospital,

Izmir 35820, Turkey

e-mail: draliyavuzcan@yahoo.com

H. Ünalp

e-mail: drhru@mynet.com
}

We report in this article two pregnant patients who underwent surgical treatment for hydatid liver cysts caused by Echinococcous granulosus.

Case 1 The patient, a 28-year-old nullipara, applied to our clinic with the complaint of abdominal pain. The patient was 13 weeks pregnant and sensitivity was determined in the right upper quadrant during the physical examination. Rebound tenderness and muscular defense were not present. WBC and hemoglobin counts were $12,400 / \mathrm{mm}^{3}$ and $11.6 \mathrm{~g} / \mathrm{dl}$, respectively. Eosinophilia was not present. The serum bilirubin, ALT, AST, and alkaline phosphatase levels were all normal. Ultrasonography (US) examination revelaled a cyst containing daughter vesicles in the fifth and sixth segments of the liver with septa and regular borders which measured $137 \times$ $190 \times 203 \mathrm{~mm}$. Intra- and extrahepatic biliary ducts were normal. The cyst was consistent a with hydatid cyst. It was determined that the single live fetus, of which the dimensions were consistent with a 13 week and 2 day fetus, had normal morphology and normal uterine hemodynamics. Serological examination revealed an indirect hemagglutinin titer of 1:1024. Subcostal incision, which is appropriate for hepatic surgery, was made. Partial cystectomy was performed. There was no bile in the cyst. The daughter vesicles and germinative membrane were totally removed. Drains were placed into and in front of the cyst. The drains were removed on the postoperative third and fifth days.

The patient did not receive additional treatment until labor. She gave birth to a healthy baby weighing $3200 \mathrm{~g}$ via vaginal delivery. After delivery a computed tomograpy scan of the thorax was performed, but no additional hydatic cyst was found.

Case 2 A 31-year-old multigravid patient was hospitalized during the 23rd week of her gestation due to the incidental 
detection of a cyst in her liver during a routine control. WBC and hemoglobin counts were $13,250 / \mathrm{mm}^{3}$ and $10.2 \mathrm{~g} / \mathrm{dl}$, respectively. USG examination revealed a cyst measuring $160 \times 150 \times 105 \mathrm{~mm}$, which was consistent with hydatid cyst. It was observed via USG that the live female fetus, of which the dimensions were consistent with a 22 week and 4 day fetus, had normal morphology and normal uterine hemodynamics. MR examination revealed a multicystic and multilobular cystic lesion measuring $175 \times$ $190 \times 110 \mathrm{~mm}$, which was located in the fifth and sixth hepatic segments (Fig. 1). Her laboratory studies were normal but indirect hemagglutinin titer was 1:512. Partial cystectomy was performed by subcostal incision. It was determined that there was bile in the cyst. The germinative membrane was totally removed. Cystobiliary connection could not be detected. Due to gestation, peri-operative cholangiography was not performed to locate the cystobiliary connection. Two drains were placed into the cyst and one was placed in front of the cyst. In the postoperative period, each drain emptied approximately $100 \mathrm{cc}$ of bile. Since the amount of the drainage was low, additional interventions were not made. Day by day, the amount of the drainage decreased. On the postoperative 14th day, biliary drainage stopped spontaneously. No additional treatment was given to the patient. At the 34th gestational week, she gave birth to a female baby weighing $2,550 \mathrm{~g}$ via vaginal delivery. After delivery a computed tomograpy scan of the thorax was performed, but no other disease was found.

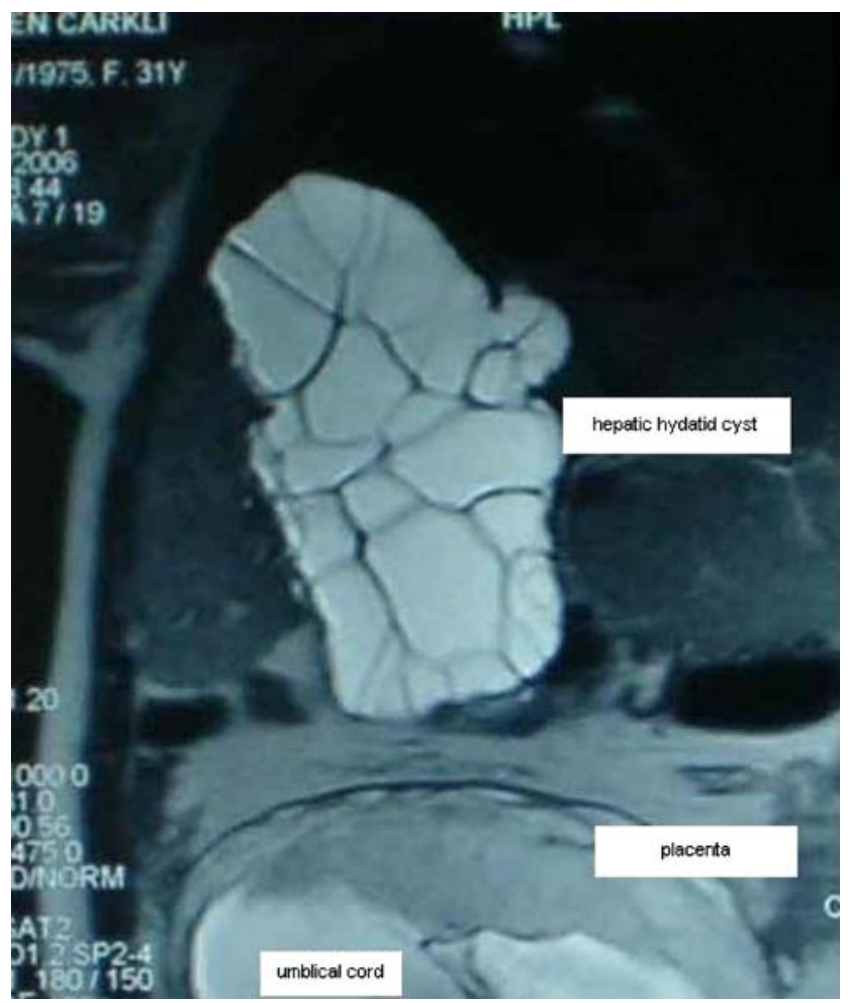

Fig. 1 Preoperative MR showing hepatic cyst, placenta, and uterus
Examinations of the patients were performed and hydatic cyst panel was applied to the patients once every 6 months. Recurrence was not determined in the patients at the end of the 14-month and 5-year follow-up examinations, respectively.

\section{Discussion}

The decrease in cellular immunity during gestation leads to the occurrence and progression of hydatic disease [2]. According to their localization, complications of hepatic hydatid cysts include rupture, anaphylaxis, and cyst torsion. As for pregnant women, complications such as abdominal pain, dystosis, delivery obstruction, and uterine rupture, which vary according to the involvement site and the dimensions of the cyst, may be seen [3]. Moreover, it has been reported that patient deaths may occur due to anaphylaxis, which results from rupture of cysts during labor [5].

Current treatment options for hydatid disease include surgery, medical treatment, and percutaneous drainage. However, it is hard to choose the method and timing for treatment in pregnant women. Some articles have shown that the administration of these drugs after the first trimester is safe $[6,7]$. Van Vliet et al. have reported that large hydatid cysts can be treated by albendazole after the first trimester [8]. The administration of anthelmintic benzimidazolecarbamate drugs is generally tolerated by the patient and partially effective. However, the two benzimidazolic drugs, namely, albendazole and mebendazole are in pregnancy category C. It has been shown in animal models that medical treatment of the disease is embryotoxic and teratogenic [9]. For this reason, the administration of these drugs to pregnant women is still controversial.

Cysts recurring after surgery or cysts that do not demonstrate regression after chemotherapy may be treated

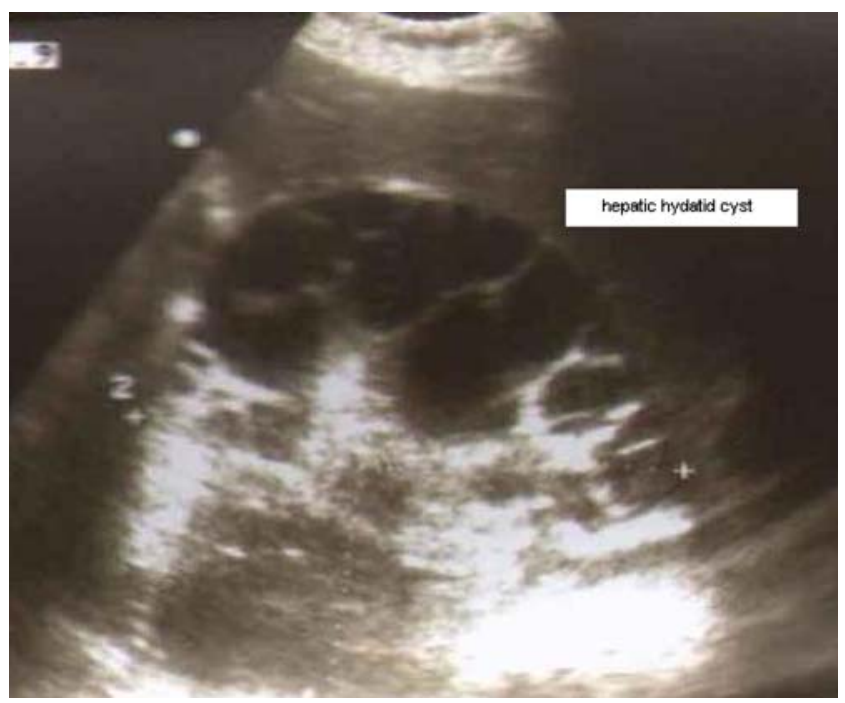

Fig. 2 Sonograpy of hepatic hydatid cyst at fifth and sixth segments 
with percutaneous drainage. The procedure is highly effective in intact univescular and multivesicular cysts with few large daughter cysts [10]. Although Ustünsöz et al. [11] reported that they had used the PAIR technique during the second trimester and obtained good results, the effectiveness of this technique during gestation is not yet well established through clinical experience. Moreover, percutaneous interventions are promising, though they are difficult to apply due to the enlargement of the uterus during pregnancy. We did not apply this technique to our patients, because the cysts in both patients were type-III cysts, and the PAIR technique cannot be done in superficial or pedinculated cysts, small volume cysts, and cysts with multiple small daughter cysts $[10,12,13]$.

Different conservative surgical approaches, such as simple cyst evacuation or partial pericystectomy, or radical surgeries such as regulated liver resection or cystopericystectomy in the treatment of liver hydatid disease have been reported [10]. Radical surgical excision, if possible, is the ideal treatment. The conservative surgical treatment, on the other hand, has risks such as dissemination, anaphylactic reactions, infection, and recurrence [14]. Information in the literature regarding surgical treatment methods for hepatic hydatic disease in pregnant patients is limited and most of this information consists of case reports $[15,16]$. A definite answer to the question, "which pregnant women should receive surgical treatment?" can not be given yet. According to Monterola et al., the indications of surgical treatment in pregnant women are as follows: (1) cysts localized in the third, fourth, fifth, and sixth hepatic segments, (2) cysts localized in the remaining abdominal organs (kidneys, spleen), (3) cysts localized in the thorax (heart, lungs), (4) cysts measuring above $5 \mathrm{~cm}$ in diameter, regardless of the involvement site, (5) sudden rupture of the cyst, (6) cysts with biliary duct connections, (7) infected cysts or hepatothoracic cyst transit, and (8) the presence of multiple cysts [17]. The cyst was localized in the 5-6th hepatic segments in our first patient and in the 6-7th hepatic segments in the second one (Fig. 2). The cyst in the second patient was multicystic and multilobular. Additionally, surgery was chosen as treatment because both cysts were larger than $5 \mathrm{~cm}$ in diameter. Although a definite period in which such patients should be operated has not been established, it has been reported that the patient should be operated if the cyst is detected in the first two trimesters. Allaert et al. reported that first trimester anesthesia exposure increased the risk of spontaneous abortion and lower birth weight. Thus, any kind of surgical intervention was avoided during the first trimester of pregnancy unless a case was compliceted with cyst rupture to the peritoneal cavity and peritonitis [18]. On the other hand, it has also been reported that the surgical treatment may be postponed for 3 months in cases when the diagnosis is made in the third trimester [17]. In our two cases, both cysts were diagnosed in the second trimester.

As a result, the treatment of hydatid disease is difficult during gestation and neither surgical nor medical treatments are completely safe. We reported in this article two pregnant patients with hepatic hydatid cysts who underwent surgical treatment without maternal and fetal complications.

\section{References}

1. Dawson JL, Stammatakis JD, Stringer MD, Williams R (1988) Surgical treatment of hepatic hydatid disease. Br J Surg 75: 946-950

2. Dede S, Dede H, Caliskan E, Demir B (2002) Recurrent pelvic hydatid cyst obstructing labor, with a concominant hepatic primary. A case report. J Reprod Med 47:164-166

3. Rahman MS, Rahman J, Lysikiewicz A (1982) Obstetrical and gynecological presentation of hydatid disease. $\mathrm{Br} \mathrm{J}$ Obstet Gyneacol 89:665-670

4. Fekih MA, Abed A, Chelli H, Khanouf M, Chelli M (1992) Pelvic hydatid cyst and pregnancy. Four cases. J Gyneacol Obstet Reprod (Paris) 21:873-875

5. Robertson M, Geerts L, Gebhardt GS (2006) A case of hydatid cyst associated with postpartum maternal death. Ultrasound Obstet Gynecol 27:636-696

6. Diav-Citrin O, Shechtman S, Arnon J, Lubart I, Ornay A (2003) Pregnancy outcome after gestational exposure to mabendazole: a prospective cohort study. Am J Obstet Gynecol 188:282-285

7. de Silva NR, Sirisena JL, Gunasekera DP, Ismail MM, de Silva HJ (1999) Effect of mebendazole therapy during pregnancy on birth outcome. Lancet 353:1145-1149

8. Van Wliet W, Scheele F, Sibingo-Mulder L, Dekker GA (1995) Echinococus of the liver during pregnancy. Int J Gyneacol Obstet 49:323-324

9. Mantovani A, Ricciardi C, Stazi AV, Marci C (1995) Effect observed on gestational day 13 in rat embriyo exposed to albendazole. Reprod Toxicol 9:265-273

10. Khuroo MS (2002) Hydatid disease:current status and recent advances. Annals of Saudi Med 22:1-2

11. Ustünsoz B, Alemdaroglu A, Bulakbasi N, Uzer AI, Duru NK (1999) Percutanous treatment of hepatic hydatid cyst in pregnancy. Arch Gynecol Obstet 262:181-184

12. WHO Informal Working Group (2003) International classification of ultrasound images in cystic echinoccosis for aplication in clinical and field epidemiological settings. Acta Trop 85:253-261

13. Gharbi HA, Hassine W, Brauner MW, Dupuch K (1981) Ultrasound examination of the hydatid liver. Radiology 139: 459-463

14. Monte H, Soetkino R, Carr-Locke DL (2002) Hydatid disease in pregnancy. Am J Gastroenterol 97:1553-1555

15. Crow JP, Larry M, Vento EG, Prinz RA (1990) Echinococcal disease of the liver in pregnancy. HPB Surg 2:115-119

16. Blochle C, Lloyd DM, Izbicki JR, Schroder S, Brolsch CE (1993) Right sided hemihepatectomy in echinococus of the liver in pregnancy. Chirung 64:580-583

17. Manterola C, Espinoza R, Munoz S, Vial M, Bustos L, Losada H, Barroso M (2004) Abdominal echinococus during pregnancy: Clinical aspect and management of a series of cases in Chile. Trop Doct 34:171-173

18. Allaert SE, Carlier SP, Weyne LP, Vertommen DJ, Dutré PE, Desmet MB (2007) First trimester anesthesia exposure and fetal outcome. A review. Acta Anaesthesiol Belg 58:119-123 